This item was submitted to Loughborough's Research Repository by the author.

Items in Figshare are protected by copyright, with all rights reserved, unless otherwise indicated.

\title{
Systems mapping for technology development in CBRN response
}

PLEASE CITE THE PUBLISHED VERSION

https://doi.org/10.1108/IJES-08-2017-0044

PUBLISHER

(c) Emerald Publishing

VERSION

AM (Accepted Manuscript)

\section{PUBLISHER STATEMENT}

This work is made available according to the conditions of the Creative Commons Attribution-NonCommercialNoDerivatives 4.0 International (CC BY-NC-ND 4.0) licence. Full details of this licence are available at: https://creativecommons.org/licenses/by-nc-nd/4.0/

\section{LICENCE}

CC BY-NC-ND 4.0

\section{REPOSITORY RECORD}

Hancox, Graham, Sue Hignett, Hilary Pillin, Spyros Kintzios, Jyri Silmari, and C.L. Paul Thomas. 2019. "Systems Mapping for Technology Development in CBRN Response". figshare. https://hdl.handle.net/2134/28471. 


\section{Emerald International Journal of Emergency Services}

\section{Systems Mapping for Technology Development in CBRN Response}

\begin{tabular}{|r|l|}
\hline Journal: & International Journal of Emergency Services \\
\hline Manuscript ID & IJES-08-2017-0044.R1 \\
\hline Manuscript Type: & Research Paper \\
\hline Keywords: & $\begin{array}{l}\text { AcciMap, NATO, Human Factors, Ergonomics, Sociotechnical Systems, } \\
\text { CBRN }\end{array}$ \\
\hline \multicolumn{2}{|l}{} \\
\hline
\end{tabular}

SCHOLARONE ${ }^{1 m}$

Manuscripts 


\title{
Systems Mapping for Technology Development in CBRN Response
}

\author{
Abstract (250 words) \\ Purpose \\ This project aimed to develop an EU sociotechnical systems map to represent a \\ harmonised concept of operations (CONOPS) as a future development platform for \\ technologies used in multi-services emergency responses to Chemical, Biological, \\ Radiological and Nuclear (CBRN) incidents

\section{Methodology} \\ AcciMaps were developed to locate where technologies are currently used, and \\ opportunities for new technologies. The AcciMaps were iteratively co-designed with \\ End Users (Fire, Ambulance, Police and Military) across three EU countries (UK, \\ Finland and Greece). Data were collected using document analysis and interviews \\ with senior ranking (Gold or Silver Command level) representatives of the \\ participating end users.
}

\section{Findings}

Despite differences in terminology and between service sectors, consensus was achieved for the command structures (Gold, Silver and Bronze), and Hot Zone responders (Specialist Blue Light Responders and Blue Light Responders). A Control Room was included as the communication spine. Blue Light Responder activities were limited by their scope of practice and available equipment, for example breathing apparatus. The harmonised EU AcciMap offers a high level sociotechnical systems map of CBRN response. Critical segments have been identified which offer opportunities for technology developments that can add value in terms of response capabilities (e.g. tag and trace).

\section{Originality/ Value}

A large scale major CBRN incident may need cross-border and cross-professional engagement where efficient interoperability is vital. This research is the first EU consensus of a sociotechnical system map for CONOPS. It supports future research 
International Journal of Emergency Services

Page 2 of 17

$$
\begin{aligned}
& 1 \\
& 2 \\
& 3 \\
& 4 \\
& 5 \\
& 6 \\
& 7 \\
& 8 \\
& 9 \\
& 10 \\
& 11 \\
& 12 \\
& 13 \\
& 14 \\
& 15 \\
& 16 \\
& 17 \\
& 18 \\
& 19 \\
& 20 \\
& 21 \\
& 22 \\
& 23 \\
& 24 \\
& 25 \\
& 26 \\
& 27 \\
& 28 \\
& 29 \\
& 30 \\
& 31 \\
& 32 \\
& 33 \\
& 34 \\
& 35 \\
& 36 \\
& 37 \\
& 38 \\
& 39 \\
& 40 \\
& 41 \\
& 42 \\
& 43 \\
& 44 \\
& 45 \\
& 46 \\
& 47 \\
& 48 \\
& 49 \\
& 50 \\
& 51 \\
& 52 \\
& 53 \\
& 54 \\
& 55 \\
& 56 \\
& 57 \\
& 58 \\
& 59 \\
& 60
\end{aligned}
$$

for technology development e.g. detection and decontamination equipment design and use, communication, diagnosis and response technologies.

Key words: (max 12) AcciMap, NATO, Human Factors, Ergonomics, Sociotechnical Systems, CBRN 


\section{Introduction}

When a mass casualty incident $(\mathrm{MCl})$ related to Chemical, Biological, Radiological or Nuclear (CBRN) agents occurs the emergency services will react rapidly to achieve the core goal of saving lives (Cornish, 2007; Alexander and Klein, 2003). The response environment will probably be hazardous and ambiguous, with key information such as the cause of the incident (natural disaster, accident or terrorism), the contaminant ( $C, B, R$ or $N$ ), the numbers of injuries and fatalities, and the stability of the working situation (and risks to responders) likely to be unknown for a period of time. The emergency services (Fire, Police and Ambulance) will be working together in situations that are high risk and time critical, with different skill sets, training, and mental models (House et al., 2014; Hodgkinson and Healey, 2008, Drabek and McEntire, 2002; Mendonça et al. 2007).

Previous incidents have identified challenges for interoperability. After the London Bombings on 7th July 2005, the Review Committee concluded that "communications within and between the emergency services 'did not stand up ... individual emergency service personnel could not communicate effectively, in some cases with each other and, in other cases, with their control rooms" (Hallett, 2011). It is acknowledged that different professional and international laws/regulations may lead to confusion and conflicts as "individual teams tend to focus on agency-specific behaviour, as opposed to coordinated multi-team functioning, and so collective interoperability is not achieved" (House et al., 2014). In large scale cross-border $\mathrm{MCls}$ there may be greater interoperability challenges as teams are likely to be working with unfamiliar, or incompatible equipment, in unfamiliar locations and "there is a need for more effective coordination between civil protection authorities at local, regional and national- as well as on a cross border basis within the EU in order to integrate response procedures" (Centre for Strategy and Evaluation Services, 2011). International co-operation is important for an effective response (Centre for Strategy and Evaluation Services, 2011) as, although "there is a low probability of these attacks ... their impact is so high that we judge preparations must be made for them. As in so many other areas of this strategy those preparations must wherever possible be coordinated with our allies overseas" (Home Office, 2011). 
CBRN advice for interoperability across borders is available from the North Atlantic Treaty Organisation (NATO, 2015) as a concept of operations (CONOPS) with guidance on procedures, capabilities and equipment. The guidelines refer to information gathering/assessment/dissemination, scene management, saving/protecting lives, and specialist support. This top-down approach to disaster management has been criticised by O'Brien and Read (2005), suggesting that the high level role of government 'will remain largely the same' whilst individual services may continue with local custom and practices, 'getting on with the job'. There is advice from the UK Government that "all individuals and organisations that might have to respond to emergencies should be properly prepared, including having clarity of roles and responsibilities, specific and generic plans, and rehearsing response arrangements periodically" (Cabinet Office, 2010).

It has been suggested that increasing awareness of cross-professional practices can improve emergency service response (Healey et al., 2009). So how can this interoperability be represented for cross-professional and cross-border working? One approach is to map the CBRN response as a sociotechnical system (STS; Carayon et al, 2015). This is "a set of inter-related or coupled activities or entities (hardware, software, buildings, spaces, communities and people) with a joint purpose links between the entities which may be of state, form, function and causation ... existing within a boundary', these will change and modify with 'inputs and outputs which may connect in many-to-many mappings' (Wilson, 2014).

A previous systems model of CBRN response used a chronological approach starting with the threat then moving through the stages of prevention, preparedness, alerting/ early response, and remediation (Healy et al. 2009). Although this is useful for establishing the response phases and events, it lacks detail about specific tasks, relationships, technologies, decision-making and lines of communication. Other systems mapping methods (e.g. AcciMaps) have been used to visualise a STS as a hierarchy with actions and lines of communication in a vertically integrated view (Salmon et al, 2012). AcciMaps were originally developed to analyse STS interacting events and decision-making processes where there were opportunities for loss of control (and accidents; Branford et al., 2009). Salmon et al (2012) commented that AcciMaps offer a good approach to represent organisation and individual interactions with multiple STS. 
There are many technologies used in a CBRN response for command and control; to manage communication and coordinate efforts of the various participants of a rescue effort (including detection, diagnosis and decontamination), and to manage access to the scene and provide security. This is a technical component of an STS which requires usable interfaces. In 2007, a Usability and Human Factors/Ergonomics (HFE) standard for medical device development was established which requires manufacturers to consider potential risks of system use and integration (IEC/ISO 62366).

This paper describes the development of a CBRN AcciMap as a STS (CONOPS) and future platform for development and evaluation of technology.

\section{Method}

The AcciMaps methodology was modified (Salmon et al, 2017) to give a prospective visual representation of hierarchies, actions and lines of communication. This aimed to develop a consensus (harmonised) cross-professional and cross-border systems map for communication, decision-making, authority/delegation, situational awareness, logistics and reporting hierarchies.

Purposive sampling was used to recruit participants to both provide relevant CONOPS documents and for interviews. As the content was sensitive and sometimes restricted, participants were recruited through project partners in the (anonymised) project. Participants were required to have experience of operating at Silver or Gold levels of command and have worked at Bronze level (Table 1) to allow exportation of all levels of the STS.

\section{$<$ Insert Table 1 here $>$}

The development of the AcciMaps used an iterative qualitative approach with empirical data collection from document analysis and interviews. Documents, both open source (e.g. NATO, 2015), and restricted (if access was approved), were read to extract task and operator information. These were separated by hierarchy (Gold to first responder) using the themes of communication, planning, action, and reflection to form the first AcciMap (Version 1; V1). This allowed visualisation of multiple tasks and responsibility levels on a single map, creating a preliminary framework. 
Where no documents were available, data were collected by interview to describe task activities starting with the first blue light responder arriving on scene and working upwards through the chains of command to detail the hierarchy, responsibilities, capabilities and resources for the STS. Field notes were recorded during the interview, transcribed and validated by the interviewees (member checked) for integration into the maps. These data were used to develop V1 mapping with tasks allocated to hierarchies and categories as with the document analysis.

The V1 map was then reviewed with a participant from each stakeholder service (Fire, Ambulance, Police, and Military) exploring any differences between the written procedure (work as imagined) and actual procedures (work as done). The AcciMaps were amended following feedback to create version 2 (V2). This iterative process continued with AcciMaps sent for responder validation and feedback, until the AcciMap was signed off as an accurate representation of each service's CBRN response.

To create the harmonised consensus, the individual AcciMaps from each service were combined into a single AcciMap to represent the CBRN response STS across the EU. Each individual AcciMap was compared and contrasted to look for similarities (rather than differences). The development of the consensus AcciMap aimed to have less detail to manage differences between services but to retain sufficient detail as a usable STS model. The same iterative procedure was followed with review, feedback and validation to all participants $(n=5)$. Every time the AcciMap was changed it was circulated to all participants to ensure that it retained validity for their individual service. This reduced the level of detail, for example tasks for triage and initial treatment can be undertaken by either Fire Service or a specialist Ambulance service depending on the territory, so the map does not assign tasks to one service. The EU AcciMap was validated by all participants as meaningful for their country.

\section{Results}

The essential tasks and operations of an EU CBRN response are shown as a harmonised (consensus) AcciMap (Figure 1) for the themes of Communication, Planning, Action, and Reflection. It was agreed that a similar structure of command 
is used across the EU with some variation in terminology; Gold is often called 'Strategic', and the terms 'Tactical', 'Incident', and 'Operational' are used interchangeably to describe either Silver or Bronze levels, depending on country and service. A unified terminology was agreed as Gold/ Strategic Command, Silver/ Incident Command, Bronze/ On-Scene Command. These levels were followed by Specialist Blue Light Responders (S-BLR) and initial Blue Light Responders (BLR).

Blue Light Responders are the conventional response individuals/ teams who respond to emergency calls. They are required to recognise that the scene may be a CBRN event and pass as much information as possible to control rooms so specialists (S-BLR), with CBRN response capabilities, can be dispatched. The level of training and personal protective equipment (PPE) will determine the tasks they can carry out. S-BLR, in these circumstances, are specially trained and equipped to react to CBRN events including triage; detecting, identifying and monitoring (DIM) the agent; casualty decontamination etc.

The participating services agreed that the Bronze/ On-Scene Command carries out tasks to ensure that all resources (equipment and personnel) are used optimally by following the Incident Command Tactical Plan (T-Plan), and Standard Operating Procedures (SOPs). They manage the Operational Plan (O-Plan) which informs the tasks to be conducted by BLR and S-BLR.

Silver/ Incident Command establishes, tracks and monitors the resources needed to perform an effective CBRN response as an on-going process throughout the incident. They are usually, but not always, located some way from the CBRN scene and have more of a systems ('bigger picture') perspective and will offer advice to the Bronze/ On-scene Command. They manage the Tactical Plan and communicate information up and down the STS, to reduce information overload for Gold and Bronze commands.

The Gold/ Strategic Command is outward facing, managing the resources (regional, national and international) needed for the response. They are the point of contact with Government representatives and give or agree messages to the public, often via the media. They instigate the Strategic Plan (S-Plan) based on policies, legal frameworks and protocols which is used by the Incident Commander (IC). Gold/ Strategic Command will consider mutual aid plans, environmental considerations 
(containing run off, blocking drains etc.), evacuation of people and resources, utility shutdowns, and return to readiness ('business as usual').

The Control Room/Dispatch activities are represented as a communication spine for transmitting information up/down the hierarchy. Most communication is by radio, with dedicated radio and wireless channels. There will often be a dedicated Major Incident Control Room (Con.Room) for each agency, with which all levels communicate for situation reports (Sit-Reps). Communication mostly takes place between adjacent levels. Bronze Command has continuous dialogue with S-BLR and BLR to give briefings and receive situation reports but will communicate with Gold Command only via Silver.

All services have procedures to ensure equivalent level Commanders are co-located (face-to-face communication) as far as is reasonably practicable. This was reported to improve the joint situation understanding, situational awareness and decisionmaking.

\section{<Insert Figure 1 here>}

\section{<Insert Table 2 here>}

Fire services (BLR and S-BLR) are responsible for detecting, identifying and monitoring (DIM) hazards using a wide range of methods and equipment (technology). This information is used to determine cordons and zones, and communicated through the command levels to develop Strategic and Tactical Plans. In most EU territories Fire services usually lead for triage and evacuation of nonambulatory casualties from the Hot Zone; they are also responsible for mass decontamination of casualties, using improvised and specialist systems depending on the location and phase of the CBRN event and available resources. In the UK the Ambulance service is responsible for clinical triage in the Hot Zone.

BLR tasks are supported or limited by the available equipment. Most Ambulance services (except UK) are not routinely supplied with Personal Protective Equipment (PPE) which allows them to enter the Hot Zone, so pre-hospital care is mostly provided in the Cold Zone. Fire services usually carry higher specification PPE, including breathing apparatus, and will enter the Hot Zone to perform snatch rescues ('heavers') and initial reconnaissance. 
Military resources and experts are used to provide support for CBRN response if required. They will be mobilised by Gold Command to increase the number of personnel and equipment to support DIM, triage, medical treatment, cordon control, mass decontamination and environmental protection/recovery, or if there is a requirement for specialist explosives capabilities (bomb disposal). It was found that Military CBRN CONOPs are well-described but the level of detail does not necessarily translate to provide specific details for civilian CONOPS. The Military role was reported to be different across the EU, related to local political and cultural norms for involvement in civilian settings as well as CBRN resources and capabilities.

As two of the participating services use the NATO (2015) guidelines to develop their operating procedures, the NATO guidelines are incorporated as follows:

1. Information gathering, assessment and dissemination is carried out by BLR and S-BLR levels, often by the Fire Service. Basic reconnaissance and DIM occurs as soon as possible depending on available equipment and PPE. The information is sent up the chain of command or to the Control Room for further dissemination.

2. Scene management (isolated and controlled for the safety). This occurs at the BLR level with initial responders evacuating and securing the Hot Zone followed by the Police services taking charge of securing the area as soon as possible. DIM information is used by Fire Services to calculate the Hot, Warm and Cold Zone boundaries; it will be monitored throughout the incident for wind changes etc.

3. Saving and protecting lives - effective methods for rescue, decontamination and medical treatment must be considered. This is done by BLR and S-BLR levels with snatch rescues, triage, treatment and decontamination. However, these tasks could be performed by difference services

4. Specialist support. This occurs at both Silver and Gold levels where contact information for specialists in chemicals, biological agents, radiological substances, environmental clean-up etc. will be in place and can be activated if necessary.

Opportunities for future technology development and evaluation were explored by locating specific technologies in individual sectors. For example, Fire service BLR 
may routinely carry DIM equipment whereas S-BLR DIM equipment may be specifically designed for prolonged use in the Hot Zone. The usability requirements (design, portability and instructions for use) will change with operational circumstances so robust technology development and evaluation is needed to support an effective CBRN response.

\section{Discussion}

The international security expert community believe there is a growing probability for CBRN attacks (Steinhausler, 2015). Alexander and Klein (2006) stated 'The reality of a CBRN event has to be accepted and, as a consequence, the authorities need to consider (and take seriously) how individuals and the community are likely to react.' The process of mapping the cross-professional and cross-border CBRN responses confirmed similarities in the structures for command and control by the End Users in the (anonymised) project [I] (Greece, Finland, Czech Republic and UK). We believe that this is likely to be the first ever EU harmonised civilian CBRN systems (CONOPS).

This civilian CONOPS has been described as an 'abstract model ... to describe how it intends to operate to achieve its goals and objectives. The CONOPS may be very high level and independent of the particular systems to be used in the organization or enterprise operations' (ANSI/AIAA, 2012). While CONOPS are intended to describe detail and sequence for rescue in order that various stakeholders can know their role and contribution within a large dynamic scene where efforts must be coordinated (Mostashari et al, 2012). A large scale major CBRN incident may need cross-border and cross-professional engagement where efficient interoperability is vital and the results of this work suggest there are at least some commonalities in approach to dealing with such an incident across services and borders. This model brings to the attention of Emergency Service representatives where these commonalities lie and therefore where interoperability should be possible. If these commonalities are built upon and the STS developed further then interoperability could be prioritised and made more robust still. The model also allows those less familiar with CBRN response procedures, but who have an impact on them- such as technology developers, to better understand how the response will play out and 
therefore optimise their technology to integrate more seamlessly within the current system- leading to an improved response for all.

It has been suggested that developing an even more detailed CBRN response model may not necessarily be advisable; there is a 'fallacy of developing all-inclusive doctrines and procedures to guide complex response. Extreme events occur infrequently, and no two are exactly the same. A comprehensive set of procedures to cover the space of possible events may be impossible to achieve' (Mendonça et al., 2007). We suggest that the overview model approach taken in this paper may be as specific as is advised or needed for mapping CBRN response, as more specific operating procedures may not be achievable. However, segments of activity have been identified within the consensus AcciMap and are being further developed for use in planning/specification research and technology development, including field technical exercises.

It is acknowledged that the study has limitations in only featuring three EU countries (UK; Greece; and Finland). However, it received a very positive response when presented within the EU Community of Users in 2017 (https://www.securityresearchcou.eu/). Some caution should be used when generalising results and we recommend that further validation will be useful, as with most research.

\section{Conclusion}

A large scale major CBRN incident may need cross-border and cross-professional engagement where efficient interoperability is vital. This research is the first EU consensus of a sociotechnical system map for CONOPS. It supports future research for technology development to improve situational awareness and response capabilities e.g. detection and decontamination equipment design and use, communication, diagnosis and response technologies.

<Insert acknowledgements here> 


\section{References}

Alexander, D.A. and Klein, S. (2003), "Biochemical terrorism: too awful to contemplate, too serious to ignore", British Journal of Psychiatry, Vol.183 No. 6, pp.491-497

Alexander, D.A. and Klein, S., (2006), "The challenge of preparation for a chemical, biological, radiological or nuclear terrorist attack", Journal of Postgraduate Medicine, Vol. 52 No.2, pp.126-131.

ANSI/AIAA (2012), "Standard G-043A-2012e guide for the preparation of operational concept documents", available at:

http://webstore.ansi.org/RecordDetail.aspx?sku=ANSI\%2FAIAA+G-043A-2012 (Accessed 28 June 2017).

Branford, K, Hopkins, A \& Naikar, N., (2009), "Guidelines for ACCIMAP Analysis”, in Hopkins, A., (Ed.), Learning from High Reliability Organisations, $\mathrm{CCH}$ Australia Ltd, Sydney, pp. 193-212.

Cabinet Office, (2010), "UK Central Government Arrangements for Responding to an Emergency", available at:

https://www.gov.uk/government/uploads/system/uploads/attachment data/file/60816/conops-2010overview.pdf (Accessed 28 June 2017).

Carayon, P., Hancock, P., Leveson, N., Noy, I., Sznelwar, L., van Hootegem, G., (2015), "Advancing a sociotechnical systems approach to workplace safety developing the conceptual framework", Ergonomics, Vol.58, No. 4, pp. 548-564.

Centre for strategy and Evaluation Services, (2011), "Ex-post evaluation of PASR activities in the field of security and interim evaluation of FP7 security research", available at: https://ec.europa.eu/home-affairs/sites/homeaffairs/files/elibrary/documents/policies/security/pdf/interim evaluation of $\mathrm{fp} 7$ security ex post pasr final report en.pdf (Accessed $1^{\text {st }}$ December 2017).

Cornish, P., (2007), "The CBRN system: assessing the threat of terrorist use of chemical, biological, radiological and nuclear weapons in the United Kingdom", available at:

https://www.researchgate.net/publication/242631947 The CBRN System Assessin 
$g$ the Threat of Terrorist Use of Chemical Biological Radiological and Nuclear Weapons in the United Kingdom (Accessed 1st December 2017).

Drabek, T.E. and McEntire, D.A., (2002), “Emergent phenomena and multiorganizational coordination in disasters: Lessons from the research literature", International Journal of Mass Emergencies and Disasters, Vol. 20 No 2, pp.197-224.

Hallett Lady Justice (2011), "Coroner's Inquests into the London Bombings of 7 July 2005: Report under Rule 43. 2011", Available at:

http://webarchive.nationalarchives.gov.uk/20120216072438/http://7julyinquests.independent.gov.uk/d ocs/orders/rule43-report.pdf (Accessed June 27th 2017).

Healey, M.P., Hodgkinson, G.P. and Teo, S., (2009), "Responding effectively to civil emergencies: the role of transactive memory in the performance of multiteam systems", Proceedings of NDM9 9th International Conference on Naturalistic Decision Making, British Computer Society, London, pp.53-59.

Healy, M.J.F., Weston, K., Romilly, M., Arbuthnot, K., (2009), “A model to support CBRN defence", Defence \& Security Analysis, Vol. 25 No. 2, pp.119-135.

Hodgkinson, G.P., Healey, M.P., (2008), "Cognition in organizations”, Annual Review of Psychology, Vol 59, pp.387-417.

Home Office, (2011). "CONTEST: the United Kingdom's strategy for countering terrorism", Available at:

https://www.gov.uk/government/uploads/system/uploads/attachment data/file/97994/ contest-summary.pdf (Accessed 25 ${ }^{\text {th }}$ June 2017).

House, A., Power, N. and Alison, L., (2014), "A systematic review of the potential hurdles of interoperability to the emergency services in major incidents: recommendations for solutions and alternatives", Cognition, Technology \& Work, Vol. 16, No. 3, pp.319-335.

IEC, (2007), "ISO 62366-1 Medical devices - Part 1: Application of usability engineering to medical devices", Geneva, International Organization for Standardization. 
ISO (2007), "ISO 14971: Medical devices -- Application of risk management to medical devices as a methodology for assessing and documenting product safety and effectiveness", Geneva, International Organization for Standardization.

Mendonça, D., Jefferson, T. and Harrald, J., (2007), "Collaborative adhocracies and mix-and-match technologies in emergency management", Communications of the ACM, Vol. 50 No. 3, pp.44-49.

NATO, (2015), "Project on Minimum Standards and Non-Binding Guidelines for First Responders Regarding Planning, Training, Procedure and Equipment for Chemical, Biological, Radiological and Nuclear (CBRN) Incidents", http://www.nato.int/nato static fl2014/assets/pdf/pdf 2016 08/20160802 140801cep-first-responders-CBRN-eng.pdf (Accessed 28 June 2017).

O'Brien, G, Read, P, (2005), "Future UK emergency management: new wine, old skin?", Disaster Prevention and Management Vol. 14 No. 3, pp.353 - 361

Salmon, P.M., Cornelissen, M., Trotter, M.J. (2012), "Systems-based accident analysis methods: A comparison of AcciMap, HFACS, and STAMP”, Safety Science, Vol.50 No. 4, pp.1158-1170.

Salmon, P.M., Walker, G.H., Read, G.J.M., Goode, N., Stanton, N.A., (2017), "Fitting methods to paradigms: are ergonomics methods fit for systems thinking?", Ergonomics, Vol. 60 No 2, pp. 194-205.

Steinhausler, F., (2015), "EU Efforts in Managing CBRN Terror Attacks", in Apikyan S., Diamond D. (Ed.), Nuclear Threats and Security Challenges, Springer, Netherlands, pp. 113-122. 
Table 1: Participants $(n=5)$

\begin{tabular}{llll}
\hline Country & Service & $\begin{array}{l}\text { Interviewees' } \\
\text { operating level }\end{array}$ & $\begin{array}{l}\text { AcciMap V1 } \\
\text { source }\end{array}$ \\
\hline UK & Police & $\begin{array}{l}\text { Silver (previously } \\
\text { Bronze and familiar } \\
\text { with Gold) }\end{array}$ & Interview \\
UK & $\begin{array}{l}\text { National Ambulance } \\
\text { Gesilience Unit }\end{array}$ & $\begin{array}{l}\text { Gold (previously } \\
\text { Silver and Bronze) }\end{array}$ & Documents \\
UK & $\begin{array}{l}\text { (NARU) } \\
\text { Fire and Rescue }\end{array}$ & $\begin{array}{l}\text { Gold (previously } \\
\text { Silver and Bronze) }\end{array}$ & Documents \\
Finland & $\begin{array}{l}\text { Service (FRS) } \\
\text { Fire Service (SSAV) }\end{array}$ & $\begin{array}{l}\text { Gold (previously } \\
\text { Silver and Bronze) }\end{array}$ & Interview \\
& Hellenic Ministry of & $\begin{array}{l}\text { Gold (previously } \\
\text { Silver and Bronze) }\end{array}$ & Interview \\
\hline
\end{tabular}




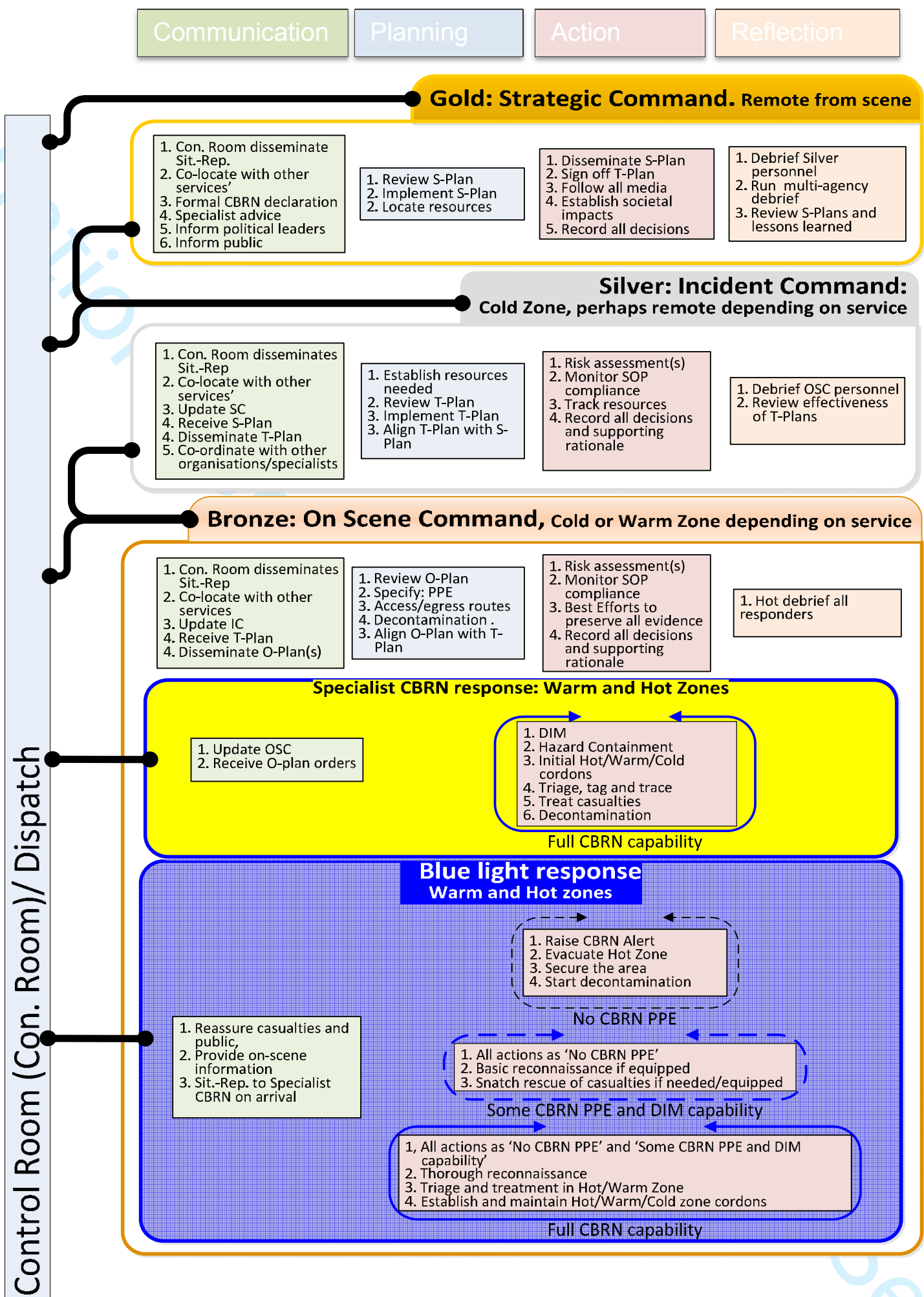

Figure 1: EU CBRN consensus AcciMap (key for terms in annex) 
Table 2: Glossary of terms used in the AcciMap

\begin{tabular}{ll}
\hline Abbreviations/ acronyms & Description \\
\hline BLR & Blue Light (First) Responder (Fire, Police, Ambulance) \\
\hline Bronze Command & Operational or Scene Command(er) \\
\hline Cold Zone & $\begin{array}{l}\text { Area safe from contamination confined by inner and } \\
\text { outer cordon }\end{array}$ \\
\hline Con.Room & Control Room for communication \\
\hline Cordon & $\begin{array}{l}\text { Physical or figurative barrier (tape or other) to indicate } \\
\text { where access may be restricted for safety reasons }\end{array}$ \\
\hline Decontamination & $\begin{array}{l}\text { Removal of substances from people, equipment or the } \\
\text { environment. }\end{array}$ \\
\hline DIM & Detection, Identification, Monitoring \\
\hline Gold Command & Strategic Command \\
\hline IC & Incident Command(er) - Silver Command \\
\hline OSC & On Scene Command \\
\hline O-PLAN & Operational PLAN \\
\hline PPE & Personal Protective Equipment \\
\hline S-PLAN & Strategic PLAN \\
\hline Silver Command & Tactical or Incident Command(er) \\
\hline SOP & Standard Operating Procedure \\
\hline S-BLR & $\begin{array}{l}\text { Specialist Blue Light Response/Responder trained to } \\
\text { deal with elements relating to CBRN. }\end{array}$ \\
\hline T-PLAN & Tactical PLAN \\
\hline Triage & $\begin{array}{l}\text { Screening and prioritization of casualties based on } \\
\text { severity of injuries }\end{array}$ \\
\hline Warm Zone & $\begin{array}{l}\text { Area not directly exposed to the substance but possible } \\
\text { exposure from people and equipment not yet been } \\
\text { decontaminated }\end{array}$ \\
\hline
\end{tabular}

